\title{
Research on Performance-based Salary Distribution System of Vocational College Teachers Based on Fair Incentives
}

\author{
Qiaoyue Zhao \\ Personnel department \\ Sichuan Vocational and Technical College \\ Suining, Sichuan Province, China
}

\author{
Ying Wei \\ English Teaching and Research Group \\ Suining Middle School \\ Suining, Sichuan Province, China
}

\begin{abstract}
Performance pay is an important part of higher vocational education with independent distribution rights. Performance salary reform is a major change in the higher vocational salary system. At present, the salary of most of the higher vocational teachers is mainly composed of three parts: post salary, salary scale salary and post allowance, which mainly reflects the influence of position and title of school staff on the individual wage income. The wages related to professional and technical career performance are only two parts of teaching and research and teaching workload, the proportion of total wages is not high, and the incentive effect is not obvious. Based on the survey results, it is found that most of current high-paying salary systems have problems such as small salary elasticity and ineffective incentive. From aspects of optimization of performance salary distribution structure and design of "menustyle" performance indicators, the design of distribution system is promoted. Performance pay reform is of great significance.
\end{abstract}

Keywords-performance-based salary distribution system; vocational college teachers; fair incentives

\section{INTRODUCTION}

In the process of modernization of higher education, the scale of higher education is expanding, and student development is oriented to gaining useful skills and knowledge, rather than just becoming a member of elite culture. Higher education has gradually changed from elite education to mass education and even to the popularization of higher education. At the same time, the laws governing the distribution of public funds in the world have also undergone significant changes--the general transfer payments from public services to the most urgent needs and should A special transfer payment shift that requires people to target. This means that education needs to compete for financial resources in many public sectors, and the development of higher education is completely unsustainable by relying on public funding. To this end, public higher education has gradually begun to implement strategies in line with global marketization prospects and new public management methods. Universities have also begun to pay more attention to the initiative of teachers in order to cope with the impact of the decline in the level of state funding, and strive to solve the external financial resources support and Committed to improving the contradiction between undergraduate teaching and increasing competition for outstanding teachers. Performance pay plans are generally adopted strategies because they take into account school assessments and performance-based funding. The use of performance methods for wage adjustment in higher vocational schools at home and abroad has become a trend. Performance payroll strategies have been implemented in most of the United States and Canada, and are often seen as part of normal teacher salaries, especially in higher-level teachers' unions. Since 2006, China has begun to explore the implementation of the post performance pay system for public institutions. In 2011, the "Guiding Opinions on Promoting the Reform of Institutions in the Classification" attributed higher vocational education to the second category of public welfare, stipulating that some of the university's resources were allocated by the market, and part of the funds were implemented financially. Further clearly expand the autonomy of running a higher vocational school. Therefore, the limited total wages make the rational distribution of performance wages more important. The rationality of the performance salary distribution system design and the fairness of the results will affect the teachers' emotions and enthusiasm to some extent, such as the 2013 Chongqing Technology and Business University teachers. Due to the unfair distribution of performance wages, the incident of singing the national anthem has been widely concerned by the media. Some highlevel jobs have also caused a lot of controversy due to the issue of teacher performance payroll. Constructing a scientific, reasonable and efficient performance payroll distribution system has become an urgent issue in the current reform of the higher vocational income distribution system.

\section{THE PRACTICAL DEMANDS OF HIGHER VOCATIONAL TEACHERS FOR FAIR INCENTIVES}

Since the Third Plenary Session of the 11th CPC Central Committee, China's economic construction has made great achievements for the world, China's comprehensive national strength has been significantly enhanced, and people's living standards have been continuously improved, laying a more solid foundation for the realization of the common prosperity goal of all Chinese people. Looking at the history of social development in ancient and modern China and foreign countries, the core and cornerstone of social justice is economic distribution equity. Since the reform and opening up along with the rapid growth of China's economic wealth and the continuous improvement of the overall income level of the 
residents, the gap between the interpersonal and inter-group incomes of the whole society has expanded rapidly, the disparity between the rich and the poor, the unfair distribution and the sense of fairness have become a very prominent society[1]. contradiction. The fair distribution of social microorganization is not only directly related to people's satisfaction, morale and behavior, but also affects the stability, efficiency and development of the organization or society. At the same time, a country's higher education is not prosperous, and it cannot surpass the world's advanced level in terms of overall national strength. Looking at the world situation, a strong country must first be strong. Today's education enters the era of strategic planning. Giving priority to the development of education has become a magic weapon for developed countries to cope with the financial crisis. As a highland for talent training, higher education shoulders the major task of cultivating high-level specialized personnel, developing science and technology culture, and promoting modernization. The rapid development of higher education has provided strong support for the transformation of China's economic growth mode and strategic adjustment of economic structure. However, under the current conditions of China's implementation of the socialist market economic system, there are unilateral ills in the pursuit of equal results in China's higher vocational teachers, and the irrational income gap between teachers. At the same time, due to the minority teachers' literary The false academics of private affairs lead to some illegal and abnormal incomes. These unfair distribution of incomes have destroyed the balance of interests among higher vocational teachers, which has caused some college teachers to have a strong psychological imbalance, which is not conducive to mobilizing the majority of teachers for China's higher education. The revitalization of education and the enthusiasm, initiative and creativity of improving the quality of personnel training have caused harm and influence to China's higher education and economic and social development. In addition, the gap between the rich and the poor in the society has been expanding at this stage, which has aroused the great attention and close attention of the people of the country, including the state leaders and ordinary people, to the issue of fairness in pay distribution [2].

\section{THE SALARY DISTRIBUTION SYSTEM OF HIGHER VOCATIONAL TEACHERS}

In order to better understand the current performance of some senior vocational performances, through the school website, school teachers, etc., to understand the salary composition and performance pay of more than a dozen highlevel jobs in Liaoning, Guangdong, Changchun, Sichuan, etc.

Salary composition The specific situation is as follows: Through the investigation, most of the current high-level salary components are divided into four parts: First, the basic salary. The second is the post allowance. The third is the reform subsidy that is reserved. The fourth is job performance salary. The first three parts are implemented in accordance with national and provincial regulations. The job performance salary usually adopts the total amount control, which is roughly divided into two parts: basic performance and reward performance. The salary structure of higher vocational education is generally consistent. The basic salary includes post salary and salary scale salary; performance salary is divided into basic performance allowance and reward performance salary, while the basic performance salary accounts for $60 \%-70 \%$, the name is basically unified, and the reward Sexual performance wages are mainly reflected in the three aspects of teaching, research and management. Looking at the wage composition of each higher vocational school, there is little difference in the overall setting. The differences in the higher vocational positions in the region are not large, but there is a big difference in the amount of the post allowance.

Salary management performance wages, allowances and subsidies Most of the higher vocational schools are managed by the school and the total amount is controlled. The colleges formulate the distribution methods and decide the allocation amount. Some schools also adopt the unified management and unified distribution methods of the schools. Compared with these schools, the management mode of a university in Chengdu is slightly different. In terms of job title, the secondlevel college has greater autonomy. The first-level position is directly employed and managed by the school. Assessment; 2 - 5 posts (including key positions of discipline responsibility, key teaching positions, key research positions) The school sets the basic criteria for competitive recruitment and performance evaluation. The college formulates specific job responsibilities, college appointment, management, assessment, school review and filing. In this way, the performance evaluation and performance salary are all independently formulated by the secondary colleges. The post allowance is also determined by the school after the total amount control, and the teachers are divided into two types: scientific research and teaching. Different performance evaluation criteria are used [3].

Distribution structure From the perspective of distribution structure, the performance salary consisting of basic performance wages and reward performance payouts varies from $7: 3$ to $6: 4$, and is mostly $7: 3$. The basic performance salary is mainly based on the system and distribution of the overall standard of the school. The basic requirements for basic scientific research and teaching workload are set according to the position and title level in advance, and are distributed on a monthly basis according to the completion status. At present, most higher vocational secondary colleges have the independent distribution rights of incentive performance pay, accounting for $8 \%-11 \%$ of the entire salary structure. Among them, the proportion of autonomous distribution rights of a university in Chengdu is relatively high, reaching about $50 \%$. Reward performance pay is mainly reflected in the aspects of excess workload, scientific research, teaching and service, including basic teaching work rewards, super research teaching workload rewards, management service work rewards and annual comprehensive nuclear awards. 


\section{PROBLEMS IN THE PERFORMANCE-BASED SALARY} DISTRIBUTION SYSTEM

The wage elasticity is small, the gap is large, and the incentive effect is not obvious. From the current salary distribution system of higher vocational education, the proportion of basic wages to total wages is about $30 \%$ or even less, and the proportion of school post allowances and bonuses is the largest. $70 \%$ or so. This part of the post allowance is mainly reflected by the basic performance salary and the incentive performance salary. Therefore, the performance salary should play an important adjustment role, so that the teacher can "earn the income" and the input effort and contribution can be deserved. Return. However, from the perspective of studying the performance-based salary distribution system of each higher vocational school, the premise of design is based on the title and position, and the boundary is obvious. There is no crossover between the performance wages between the professional titles at the same time, and the performance salary between each title level. The gap is also large, the higher the title, the more obvious the gap. Therefore, the salary of teachers is closely related to the title. Only through the promotion of professional titles can wages be increased. In the same title level, the difference in teacher wages is small, and the elasticity of performance adjustment is small. In addition, due to the large gap between low-level wages and high-level wages, due to the current salary system, the low-level teachers in the school's previous wage growth, the growth rate is the smallest, and the current structure of higher-level teachers, There are a lot of young and middleaged teachers with low professional titles, which is very unfavorable for the growth of young and middle-aged teachers Wages have not played their due role. At the same time, young and middle-aged teachers realized that if they want to raise their wages, they can only rely on the promotion of their titles. Due to various restrictions and other reasons, the school's job title promotion competition is becoming more and more fierce, and the number of places is getting less and less, which makes teachers very utilitarian in many daily work, the harmonious development of the school and the growth of young teachers are very unfavorable [4].

The setting of performance pay is heavy "quantity" and "quality". The evaluation index of post allowance and job allowance in post allowance is based on the completion rate of teaching workload, and there are obvious evaluation criteria, but there is no "quality". In terms of indicators, only the teaching workload can be completed, and all the post allowances and job allowances can be obtained. The sum of the two parts accounts for more than $95 \%$ of the total post allowance, which means that as long as the workload is completed, the post allowance is basically sufficient. However, for the completion of the teaching work, the teaching effect is not included in the evaluation standard. Although the teaching evaluation work is carried out at the end of each semester, the results of the teaching evaluation are not applied, which leads to the teacher's gradually only teaching work. Pay attention to the completion of your teaching work, and not pay too much attention to the good or bad of the completion, which is unfavorable for the improvement of the teaching level of the school.
The scientific research subsidy has little incentive for scientific research work. One of the post allowances is a research subsidy. According to the professional title structure of the teacher, a certain scientific research workload standard is set. If the completion is not completed, the corresponding scientific research allowance is deducted. Compared with the total amount of post allowance, the proportion of research subsidy is only less than 5\%. Take a lecturer of a high-ranking post in Sichuan as an example. The research subsidy of 100 yuan per month, even if it is not allowed, is only deducted 100 yuan, so the strengthening effect is not great, so many people do not pay enough attention to the research subsidy, and it has little effect on stimulating the interest of teachers in scientific research.

Designing only the minimum standards. For the ultra-high standards, there is no design because of excessive "fairness", so that each higher vocational school has only a minimum completion standard line in terms of the performance salary design of the teachers. Even all, but for those who are particularly outstanding, they have a lot of teaching tasks and have made great contributions to the teaching work, and they have not given corresponding rewards. For scientific research allowances, there are also such problems, and they have completed basic research. Allowance, but if it is overcompleted and there is no corresponding reward, such a design is not conducive to producing excellent results, and doing the same is good, which is not conducive to the rapid development of the overall teaching team [5].

For the division of scientific research and teaching teachers, it is not obvious that the existing salary system has no obvious difference with the types of teachers. This may be particularly good for those teaching work, but the research is slightly poor, and the research ability is very good. Strong, but teachers with weak teaching ability are very unfavorable, and can not achieve the incentive effect of "doing the best."

\section{OPTIMIZATION DESIGN OF PERFORMANCE SALARY} DISTRIBUTION SYSTEM FOR HIGHER VOCATIONAL TEACHERS

Optimizing the performance salary structure Herzberg proposed the "two-factor" incentive theory, which divided the incentive factors into health care factors and incentive factors. The performance salary of higher vocational education includes basic performance salary and reward performance salary, which play the role of health care and encouragement respectively. The basic performance includes the basic completion standards of teaching and the basic completion standards of scientific research. For the teachers with administrative duties, the job allowance is designed. For the reward performance pay, the corresponding performance evaluation indicators are broken according to the professional titles. According to the teaching and research aspects, Mainly reflected in the additional contribution to teaching and research, such as access to teaching evaluation, teaching results, research topics and patents; at the same time, increase the proportion of reward performance pay in performance pay, from the majority of the original $7: 3$ to $6: 4$, to play a real incentive effect, so that performance pay can play its due role.

"Menu-style" performance evaluation index design In addition to adjusting the structure of performance pay, in order 
to maximize the performance of performance pay, after the redesign of the salary structure, effective performance evaluation indicators are needed. It directly determines the effectiveness of performance-based salary optimization. For performance appraisal indicators, there are two parts in the first-level indicators. One is basic performance-based payroll, which mainly serves as a guarantee function. In addition to focusing on teaching workload and scientific research completion, indicators are designed to complete the school. The reward wages should include three parts, part of the effect of teaching completion, part of the completion effect of scientific research, part of service performance, that is, some basic and additional work for colleges and colleges, such as participation Assessment-work, the establishment of the college's rules, the maintenance of the college's website, etc., so that teachers can work in their own sub-divisions, and they can get practical exercise. Finally, in addition to the basic + reward performance pay, you can design some excellent bonuses. The design of this bonus is mainly reflected in some special contribution awards to colleges and schools, namely performance pay $=$ basic performance + reward performance Salary + bonus.

According to the weight of indicators, the design of teaching and research-based indicators can further decompose performance wages, that is, performance salary $=$ basic teaching weight $*$ teaching work completion index + basic research weight $*$ research completion index + job allowance + reward teaching weight $*$ Teaching Excessive Indicators + Incentive Research Weights* Research Over-Completion Indicators + Special Contribution Bonuses. Because the design of the weights is different, it has different effects on the overall level of teachers' wages. Therefore, the index weights can be divided into two grades, namely, teaching type or scientific research type. If the teaching type is selected, the weight of teaching in the salary is Will account for about $70 \%$, and if you choose scientific research, the proportion of scientific research is $70 \%$, teaching is only $30 \%$, in the perspective of moderate fairness, the school controls the total amount of two types of teachers, reasonable formulation. The corresponding work completion indicators, and surveys in the teacher group, after several presets and revisions of the indicators, finally determine the two different performance evaluation indicators and salary plans for teaching and research, so that teachers can play their own strengths.

Improving the performance-based payroll management system In order to reflect "appropriate fairness", the management of performance payrolls is controlled by the total amount of schools and the independent control of secondary schools. The basic performance salary part can be uniformly formulated by the school and implemented uniformly; for the reward performance salary, the distribution right is decentralized to the secondary college, and a special performance appraisal group is set up. On the basis of the total amount control of the school, the college introduces a specific distribution. The rules, self-developed evaluation criteria for scientific research, teaching, service and bonuses, the school passed the examination, the assessment cycle and the specific assessment subject. The secondary college regularly adjusts and revise the evaluation criteria for reward performance pay, and publicizes the revised results, reflecting procedural fairness and fair distribution.

Continuous improvement of performance indicators In order to better fulfill the incentive effect of reward performance pay, it is also necessary to improve the performance evaluation system and corresponding evaluation indicators, such as teaching effectiveness assessment, now the teacher's teaching effect is mainly through the way of teaching evaluation And supervising the teaching evaluation awards for lectures, but the current index system for teaching evaluation is not particularly perfect. For example, all the rules cannot be excellent, and the indicators for evaluation are only measured in terms of classroom work and punctuality of teaching. Teaching attitudes and teaching methods are not fully displayed. On the other hand, the teaching evaluation awards only play a role in some teachers, and there is no way to cover all teachers. Therefore, how to evaluate the teaching effect and how to calculate the scientific research workload is more scientific and reasonable. As well as the content of the service allowance and the calculation method of the bonus, these are the key factors determining whether the reward performance salary can be successfully realized. Therefore, the improvement of the performance evaluation index is crucial.

Guarantee the reform of performance wage distribution On the one hand, it is necessary to do a good job of docking the reform of the old and new systems. The most critical factor in the smooth transition between the old and new systems is that they are recognized by most teachers, and they are slowly transitioning from acceptance to acceptance. Therefore, in the process of docking, the school can carry out the basic cognitive stage through preaching, mobilizing the conference and training lectures, and then publicize through the daily common methods such as the school website and employee handbook, thus realizing the formation of performance-based wage theory. Subtle nurturing goals. On the other hand, under the premise of ensuring incentives, it is necessary to pay extra attention to the impact of changes in wages before and after the teacher, to ensure a smooth transition of wages, and to make the performance wage reform go smoothly.

\section{CONCLUSION}

Through theoretical exploration and practice, we will consider the salary strategy of higher vocational education from a long-term perspective, establish a combination of performance and development strategies, link salary and work performance, encourage talent innovation, and work incentive mechanism, and gradually form a wage distribution and monetization welfare system. The combination of short-term incentives and long-term guarantees is conducive to the sustainable development of higher vocational salaries.

\section{ACKNOWLEDGMENT}

This project is supported by Foundation for Humanities and Social Sciences Projects of Sichuan Provincial Department of Education (Project No.: 18SB0703). 


\section{REFERENCES}

[1] Yuan Ben-fang, HE Xiang-lin. Reflections on the Fairness of Performance Salary Distribution in Colleges and Universities_—Based on Comparative Analysis of the School-based Subsidy System of the "211" Universities in Five Places [J]. Education and Economy, 2011(2):49-53.

[2] YU Wei, MA Liangliang, WANG Yapeng. Research on the Performance Distribution System of College Teachers Based on Moderate Fairness[J]. Foreign Trade, 2018, No.286(04):122-125.

[3] Chen Xiaohong. Empirical research on performance-based wage system in colleges and universities based on the analysis of fairness theory [D].123.

[4] Liu Si. Research on the performance salary system of G school based on fairness theory [D]. 2016.58.

[5] Zhu Honghao. Research on the Design of Teacher Salary System Based on Higher Vocational Colleges [J]. Economic Research Guide, 2009(31).95. 